\title{
Editorial
}

\section{Sobre Artigos Derivados de Dissertações e Teses}

É com imensa satisfação que entregamos a nossos leitores o número dois do volume 15 de Psicologia: Teoria e Pesquisa, com o qual completamos cinco números entregues no intervalo de um ano (abril de 1999 a abril 2000), ou seja, um número a cada dois meses e meio. Além disso, esperamos completar este volume no mês de junho, concluindo a edição dos números atrasados e, dessa forma, ter a publicação regularizada.

Ficamos satisfeitos, também, por observar o crescente volume de novos manuscritos que temos recebido. Nos quatro primeiros meses deste ano, recebemos o total de 25 , o que significa uma média de 6,2 manuscritos por mês. No mesmo período do ano de 1999, recebemos apenas o total de 11 manuscritos. Por outro lado, observamos que há um ano (de maio de 1999 a abril de 2000), desde que intensificamos a produção de nossos números atrasados, recebemos para avaliação o total de 62 manuscritos. Assim, mantendose a média de 6,2 manuscritos por mês, ao final deste ano teremos recebido cerca de 74 , contra a média de 47 recebidos anualmente nos últimos três anos.

Grande parte desses manuscritos foi derivada de dissertações de mestrado ou de teses de doutorado, fato comum na comunicação científica. De acordo com Meadows (1998/ 1999), talvez um quinto dos artigos de periódicos nas ciências em geral e nas ciências sociais tem origem nas pesquisas relatadas em teses, e muitas delas podem ser transformadas em livros. Todavia, ressalta esse autor que, mesmo tendo a extensão de um livro em termos de volume de conteúdo, as teses "raramente são aceitas para publicação como livro sem antes passarem por grandes mudanças". Ou seja, ele acrescenta: "É preciso modificar o estilo, a organização e os pontos de destaque, o que geralmente implica em reescrever toda a tese" (p. 165).

Dificuldades talvez maiores apresenta a transformação de um mestrado em artigo de revista científica, sobretudo para novatos. A prática de gestão editorial mostrou-nos que a conversão mal sucedida de uma dissertação em artigo quando este não é rejeitado de imediato por não adequar-se ao estilo de artigo de revista científica -, coloca o autor em uma situação na qual ser-lhe-ão feitos repetidos pedidos de reformulações formais e de conteúdo, até que o manuscrito possa alcançar uma forma publicável. Com isso, temos então um processo de tramitação excessivamente longo, desgastante e frustrante para todos: autores, editores, consultores, conselheiros e revisores.

É, pois, no sentido de tentar minorar as dificuldades inerentes a tal conversão e, conseqüentemente, tornar mais ágil o processo de produção editorial, que apresentamos um resumo da orientação do Manual da APA (1994) para os fins de (1) organização da estrutura do material da dissertação sob a forma de artigo de revista e (2) ajustamento ao estilo de escrita que é próprio de artigo.

\section{Estrutura: Extensão e Seletividade}

A primeira orientação refere-se à extensão do manuscrito, que deve conter em, no máximo, trinta páginas, uma pesquisa relatada em cerca de duzentas páginas ou mais. A tarefa de redução deve ser feita, então, com muita cautela para que a substância do relato da dissertação seja preservada. E a chave para a redução bem sucedida do tamanho está na seletividade, pois há uma série de detalhes importantes para a dissertação que são irrelevantes para o artigo.

Quando um candidato defende uma dissertação de mestrado ou uma tese doutoral, espera-se que ele diga tudo sobre o problema de pesquisa que tomou para investigação. Ele precisa demonstrar que tem conhecimento aprofundado do tópico em questão e também precisa provar que é capaz de efetuar pesquisas sobre o problema. Por isso as teses tendem a ser prolixas. Por natureza, ela pede o detalhe; a demonstração de que o tema foi apreendido. Dessa forma, tendo em vista a diferença entre os dois canais de comunicação da produção científica, a dissertação e o artigo de revista, o Manual da APA oferece alguns pontos específicos para ajudar os autores na seleção do material e na construção da brevidade do texto, os quais resumimos com alguns comentários e acréscimos nossos neste editorial.

Uma dissertação pode tratar de várias dimensões distintas de um problema de pesquisa. Sendo este o caso, o autor do artigo deverá colocar seu foco em um tópico específico. Ele deverá, também, controlar a apresentação dos resultados expostos no artigo. Nas dissertações, todos os resultados são relatados, mas no artigo sua exposição deve ser seletiva; interessa apenas o relato dos resultados significantes. Os resultados "quase significantes" devem ser excluídos. A seletividade toca, também, as referências bibliográficas e as citações. Nas dissertações, a revisão da literatura tende a ser exaustiva. Para o artigo devem ser selecionadas apenas as referências mais proeminentes. Além disso, acrescentemos que o autor deve evitar as longas transcrições de textos de autores citados. Transcrições e longas transcrições ajustamse bem ao modelo da tese, mas, nos artigos, acabam muitas vezes servindo como bloqueadores da leitura. A inserção de transcrições de passagens de outros autores no próprio texto não deve impedir a fluência da leitura.

Com relação à seletividade, o Manual da APA (1994) faz duas recomendações adicionais. Primeiro, que o autor evite cair nas ciladas em que caem muitos autores novatos. Como exemplos destas, ele oferece dois casos típicos: (a) o relato de que "os dados foram analisados por meio de um certo pacote estatístico de computador", e (b) o caso em que "resultados significantes são apresentados na seção de Discussão" (p. 337). Já a segunda recomendação pede que o autor atente para o fato de existirem certas convenções que valem para as dissertações, mas que não se prestam para o formato 
de apresentação de artigos de revista. Uma convenção válida para as dissertações doutorais é a seção de Definições. Essa popular seção das teses é dispensável nos artigos. De acordo com o Manual, a presença de uma seção de definições em um artigo pode ser vista pelos pares revisores "como um sinal de ingenuidade em relatos de pesquisa" (p. 337).

\section{Estilo de Escrita e Economia de Expressão}

Para evitar problemas estilísticos, a primeira orientação aos autores é que iniciem a reformulação por meio da identificação das diferenças entre os requisitos da universidade na qual a dissertação foi defendida e os requerimentos do estilo APA. Tais diferenças referem-se a modos de apresentação de tabelas, figuras, referências e à organização das seções.

No que diz respeito à qualidade da escrita, a parte do Manual (1994) que trata da conversão de teses em artigos explora pouco esse aspecto. Seu tratamento mais pormenorizado encontra-se no segundo capítulo dedicado aos problemas de escrita na expressão de idéias e, mais especificamente, sua orientação para a prática de uma "economia da expressão". A grande vantagem é que o uso econômico das palavras tornaria o manuscrito mais legível e, em consequiência, aumentaria suas possibilidades de aceitação. Assim, o Manual faz a seguinte recomendação:

Diga apenas o que precisa ser dito. O autor que é frugal com as palavras não somente escreve um manuscrito mais legivel, mas também tem maiores chances de que este venha a ser aceito para publicação. Os editores trabalham com um número limitado de páginas e, portanto, com freqüência, requisitam dos autores a redução dos manuscritos submetidos. (p. 26)

Além da frugalidade, na continuação dessa passagem, o Manual (1994, p. 26) indica alguns meios concretos para o autor fazer a redução. Ela é feita "pela eliminação de redundâncias, da prolixidade, do jargão, da atitude evasiva, do excesso de uso da voz passiva, da circunlocução e da prosa informe". Outro procedimento objetivo para implementar a redução é a eliminação do desnecessário: "Elimine descrições detalhadas de aparelhos, participantes ou procedimentos (particularmente se os métodos foram publicados em outro lugar, caso no qual você deve simplesmente citar o estudo original)". E, por fim, as recomendações sobre o uso da economia de expressão pedem que o autor elimine "embelezamentos gratuitos; elaborações do óbvio; e observações ou apartes irrelevantes".

\section{Interpretação dos Dados}

Neste aspecto, o problema que o Manual (1994) destaca é o da superinterpretação dos dados obtidos em pesquisas que deram origem às teses e dissertações por parte dos próprios autores. O Manual salienta que a expectativa de problemas de superinterpretação em teses não é descabida porque os candidatos investem muito tempo e muita energia em seu empreendimento acadêmico, a ponto de enviezarem seu olhar. A superinterpretação dos dados, diz o Manual, aparece como um problema comum nos manuscritos pobremente preparados. Assim, contra a fé que pesquisadores inexperientes têm na força de seus resultados, ele declara que, "ir além dos resultados pode resultar de um sentido de propriedade e orgulho" do autor, mas que este, ao escrever seu artigo, "mostre controle ao formar suas conclusões" (pp. 337-338).

Isto posto, vejamos como o Manual (1994) sumariza a diferença entre os dois canais de comunicação de resultados de pesquisas:

Comparado com a dissertação, o artigo de revista requer uma estrutura teórica mais reduzida, uma revisão mais suscinta da literatura, uma apresentação mais controlada da metodologia e uma discussão dos resultados mais limitada. (p. 339)

Para concluir, uma observação a respeito das idéias de redução e conversão de formas de escrita veiculadas pelo Manual (1994). Ressalto o fato de que a derivação de artigos do material de teses de doutorado e dissertações de mestrado implica algo mais que a simples redução de tamanho ou reorganização e reescrita de partes do texto da dissertação ou tese. Assim, não se trata de tomar o texto da dissertação e tentar apenas reduzi-lo. $\mathrm{O}$ artigo precisa ser pensado como "derivado" ou "extraído" do material de tese ou dissertação. Trata-se da elaboração de um escrito sob a forma de artigo que toma por base o material exposto na tese ou dissertação defendida. É um novo escrito que remete integralmente ao anterior mas dele difere na forma. Em suma, artigo de revista científica, dissertação de mestrado, tese de doutorado, livro, resumo de congresso são, como salientou Meadows (1998/1999), "canais de comunicação" diferentes para a divulgação de pesquisas realizadas ou em realização, e devem, portanto, ser tratados de acordo com suas particularidades.

Esperando que estas notas editoriais possam ser úteis aos novos autores, entregamos este número bastante expressivo de tendências da psicologia brasileira.

\section{Referências}

American Psychological Association (1994). Publication Manual (4. ed.). Washington, DC: Autor.

Meadows, A.J. (1999). A comunicação científica. (A.A. Briquet de Lemos, Trad.). Brasília: Briquet de Lemos/Livros. (Trabalho original publicado em 1998)

Norberto Abreu e Silva Neto 